\title{
Representación discursiva sobre la homosexualidad en el manual diagnóstico y estadístico de trastornos mentales (revisión de 1995)*
}

\author{
FERNANDA TÉLLEZ VEGA** \\ fernandatellezvega@gmail.com
}

Recepción: 29 de noviembre de 2013

Aprobación: 06 de mayo de 2014

Forma de citar este artículo: Téllez Vega, F. (2014). Representación discursiva sobre la homosexualidad en el manual diagnóstico y estadístico de trastornos mentales (revisión de 1995). Cuadernos de Lingüística Hispánica, 25, 143-162. Tunja: Uptc.

* Artículo de investigación. Es el tercero de una indagación sobre homosexualidad que inició en el año 2012. Gira en torno a una línea de investigación central sobre lenguaje, discurso y sociedad. Con este trabajo se presentaron ponencias en el III Congreso "ciencias, tecnologías y culturas. Diálogo entre las disciplinas del conocimiento. Mirando al futuro de América Latina y el Caribe. Hacia una internacional del conocimiento" Universidad de Santiago de Chile, y en la red INAV de España, en el evento titulado III Encuentro de la red INAV, I Congreso Internacional Narrativas Audiovisuales: Convergencia mediática, transnacionalización e intercambio cultural.

** Economista de la Universidad Industrial de Santander, Colombia. Integrante del Grupo de investigación GLOTTA. 


\title{
Resumen
}

En el presente artículo se resalta la construcción y significación discursiva que da el sistema DSM IV (Manual Diagnóstico y Estadístico de Trastornos Mentales) a la homosexualidad, entendiendo que el significado que hace referencia al contenido interno del discurso y a la significación concierne al contenido externo (visible). El método de investigación se concentra en el análisis de contenidos: discusión, críticas y descripción de la metodología constructiva del manual. La técnica que se adelantó fue la de análisis de contenidos; identificación del discurso dominante y estilo. Los resultados descritos evidencian que la forma dominante del discurso es institucional frente a las formas no discursivas (sexuālis diversus). No se evidencian cambios en el discurso psiquiátrico porque su método de construcción es de retroalimentación circular, es decir, en algún lugar del proceso, la homosexualidad será considerada como un trastorno o como un tema de revisión psiquiátrica. La investigación revela que el sistema DSM IV se ajusta a la construcción discursiva poder-saber ampliamente documentada por Foucault en la que el discurso dominante ejerce poder sobre las sexuālis diversus, las define en un ejercicio del saber y las inscribe en un manual diagnóstico.

Palabras Clave: homosexualidad, sexuālis diversus, Manual diagnóstico, análisis crítico del discurso, análisis de contenidos y construcción discursiva.

\section{Discursive representation of homosexuality in the Diagnostic and Statistical Manual of Mental Disorders (1995 revision)}

\begin{abstract}
This article highlights the discursive construction and significance of homosexuality in the DSM IV system (Diagnostic and Statistical Manual of Mental Disorders), understanding that the meaning referring to the internal contents of the discourse and signification concerns the external (visible) contents. The research method focuses on content analysis: discussion, critique and description of the manual's constructive methodology. The content analysis technique was applied; including identification of the dominant discourse and style. The results evidence that the dominant discursive shape is institutional regarding the non-discursive forms (sexuālis diversus). No changes in the psychiatric discourse are evidenced, because of its circular feedback construction method; in other words, somewhere in the process, homosexuality will be considered as a disorder or as a topic of psychiatric revision. The research reveals that the DSM IV system adjusts to the power-knowledge discursive construction widely documented by Foucault, in which the dominant discourse exerts power over the sexuālis diversus, defining them in an exercise of knowledge and registering them in a diagnostic manual.
\end{abstract}

Keywords: homosexuality, sexuālis diversus, diagnostic manual, critical discourse analysis, content analysis, discursive construction 


\section{Représentation discursive sur l'homosexualité dans le Manuel Diagnostique et Statistique de Troubles Mentaux (révision de 1995)}

\section{Résumé}

Dans cet article on remarque la construction et signification discursive apportée par le système DSM IV (Manuel Diagnostique et Statistique de Troubles Mentaux) á l'homosexualité, en comprenant que le signifié qui fait référence au contenu interne du discours et à la signification, concerne le contenu externe (visible) (visible). La méthode de recherche se concentre sur l'analyse de contenus: discussion, critiques et description de la méthodologie constructive du manuel. La technique avancée a été celle de l'analyse des contenus, l'identification du discours dominant et le style. Les résultats décrits mettent en évidence que la forme dominante du discours est institutionnel face aux formes non discursives (sexuālis diversus). Il n'y a pas d'évidence de changement dans le discours psychiatrique parce que sa méthode de construction est de rétro-alimentation circulaire, c'est-à-dire, quelque part dans le processus, l'homosexualité sera considérée comme un trouble ou comme un sujet de révision psychiatrique. La recherche révèle que le système DMS IV s'adapte à la construction discursive pouvoir-savoir, documentée de manière considérable par Foucault, dans laquelle le discours dominant exerce du pouvoir sur les sexuālis diversus, les définit dans un exercice du savoir et les inscrits dans un manuel diagnostique.

Mots clés: homosexualité, sexuālis diversus, Manuel diagnostique, analyse critique du discours, analyse de contenus et construction discursive.

\section{Representação discursiva sobre a homossexualidade no Manual Diagnóstico y Estadístico de Trastornos Mentales (revisão de 1995)}

\section{Resumo}

No presente artigo se ressalta a construção e significação discursiva que dá o sistema DSM IV (Manual Diagnóstico e Estatístico de Transtornos Mentais) à homossexualidade, entendendo que o significado que faz referência ao conteúdo interno do discurso e à significação concerne ao conteúdo externo (visível). 0 método de pesquisa se concentra na análise de conteúdos: discussão, críticas e descrição da metodologia construtiva do manual. A técnica usada foi a de análise de conteúdos; identificação do discurso dominante e estilo. Os resultados descritos evidenciam que a forma dominante do discurso é institucional frente às formas não discursivas (sexuālis diversus). Não se evidenciam câmbios no discurso psiquiátrico porque seu método de construção é de retroalimentação circular, ou seja, em algum lugar do processo, a homossexualidade será considerada como um transtorno ou como um tema de revisão psiquiátrica. A pesquisa revela que o sistema DSM IV se ajusta à construção discursiva poder-saber amplamente documentada por Foucault na qual o discurso dominante exerce poder sobre as sexuālis diversus, as define em um exercício do saber e as inscreve em um manual diagnóstico.

Palavras Chave: homossexualidade, sexuālis diversus, Manual diagnóstico, análise crítica do discurso, análise de conteúdos e construção discursiva. 


\section{Introducción}

El Análisis Crítico del Discurso es un estudio del contexto en que se produce un discurso y una disertación sobre las relaciones establecidas con un sistema de poder. La homosexualidad como tema de discusión dentro de la siquiatría es la ocupación crítica del presente artículo. De acuerdo con Ariés (1987, p. 3), "El debilitamiento de las restricciones que pesan sobre la homosexualidad es uno de los rasgos más sobresalientes de la situación moral actual en las sociedades occidentales". El aplacamiento de las restricciones, actualmente, en las prácticas psiquiátricas, clínicas y de diagnóstico pertenecen a un "régimen Victoriano" (Foucault, 1998, p. 10). Sus cursos históricos fingen devoción y escrúpulos, una hipocresía en torno a los temas sexuales que continúa.

El sistema discursivo del Manual Diagnóstico y Estadístico de los Trastornos Mentales en su versión IV (DSM IV, en adelante, DSM, Diagnostic and Statistical Manual of Mental Disorders: DSM-IV ${ }^{1}$ no incluye de manera directa a la homosexualidad como una enfermedad. Para vislumbrar ese cambio en el sistema de referencia se precisa leer la sección titulada Trastornos sexuales y de la identidad sexual para develar su construcción discursiva y sus pretensiones cientificistas, que en sumatoria son un trabajo empírico que menciona el orden de las nuevas cosas que se contabilizan: trastornos y trastornados (Historia de la comorbilidad).

La historia reciente de la homosexualidad como concepto y objeto de estudio dibuja un derrotero que se ha de seguir. Al respecto, las manifestaciones academicistas inician con el reconocido artículo de Carl Friedrich Otto Westphal. El autor describe los "sentimientos sexuales contrarios", homosexuales (1870, p. 73). Michel Foucault (1998) referencia en su libro Historia de la Sexualidad I como la concepción moderna de la homosexualidad y la marginalidad que se inyecta a la representación discursiva al considerarse un tema superado en la historia moderna aún guarda vestigios de desviación.

Otras publicaciones de talante diferente, pero significativo para la concepción y construcción discursiva <práctica>, son 'la guía del joven', escrita por William Andrus Alcott (1836) y 'Lección sobre la castidad para los jóvenes', de Sylvester Graham (1911). Estas lecciones y guías son un reflejo de la situación moral de 1834, anterior a la publicación Westphal. Los textos proscriben la homosexualidad y la masturbación, a diferencia de la publicación de 1870 que se aleja del plano moral. Estas publicaciones son ejemplos para

1 En esta parte del texto se debe referir la cátedra de Michel Foucault dictada en 1970, titulada "El orden del discurso". Se dice que la construcción de un discurso, por parte de un individuo, puede ser peligrosa, puesto que las formas institucionales que pesan sobre ese discurso superan y determinan todo el proceso de creación o construcción del discurso mismo. Por ello, el manual DSM IV como institución que lleva consigo un discurso es un caso de estudio pertinente para el análisis crítico del discurso. 
promover una filosofía que difiere de la contemplación clínica; no obstante, tienen puntos de inflexión respecto a los manuales clínicos. ${ }^{2}$

La construcción discursiva de un manual médico, entendido como lo más sustancial de la materia o tema, señala su valor de uso respecto al individuo que lo orienta a la praxis. La construcción del poder se funda en la costumbre o práctica habitual, por ello se lleva a la figura de un proceder establecido en la tradición, que es repetición, además, adquirir la fuerza de precepto. La hipótesis central del presente texto indica que la representación discursiva homosexual en el manual siquiátrico DSM IV sigue siendo la misma desde el primer manual, es decir, que la institución de este sigue validando a la homosexualidad como enfermedad, aunque no se diagnostique de manera directa, sino de manera soslayada como homosexualidad egodistónica ${ }^{3}$. Esta hipótesis se soporta en los trabajos de Michael Foucault, constata su vigencia (Foucault, 1999, p. 80) y Teun Van Dijk (2000, p. 101). Es un eco de las investigaciones citadas.

Los manuales son el resumen de acciones políticas que buscan justificar un orden sexual (correcto e incorrecto), además de justificar la institucionalidad de los hospitales psiquiátricos y el ejercicio mismo de la profesión (Gamboa, 2006, p. 286). Por su parte, Michel Foucault ubica los inicios de nuestra moral sexual a finales del siglo XVII, época en la que comienza a desaparecer la flexibilidad sexual característica de tiempos anteriores. A la par del surgimiento del capitalismo y de la clase victoriana se inician cambios que aún permanecen en el imaginario actual (Gamboa, 2006, p. 247).

\section{Metodología}

Para entrar en materia, se efectúa un breve recuento del manual, con el ánimo de contextualizar el trabajo que constituye una primera etapa dentro del análisis crítico del discurso. En un segundo momento, se describe el método de elaboración DSM IV; en tercer orden, se evidencia el objetivo analítico del discurso: remarcar la relación que existe entre el poder y el saber en la descripción del método de construcción del manual, críticas y técnicas del ejercicio del poder. Finalmente, se concluye sobre esta primera etapa de discusión, puesto que este texto corresponde a una etapa preliminar dentro del análisis crítico del discurso. A continuación, en el esquema presentado se hace plausible la metodología por seguir.

2 En el manual siquiátrico el lenguaje parece neutro, pertinente al léxico científico siguen significantes discursivos conciliatorios. Ahora bien, se debe observar con detenimiento el uso de las palabras que indican la desviación y el cómo valorar o diagnosticar dentro de las premisas del manual.

3 Conflictos con el sistema de coherencia entre la autoimagen y el ego del individuo. 
Debe mencionarse que el armazón metodológico reposa en Norman Fairclough (ver figura 1.0) que es la sistematización del problema presentado. Por motivos de extensión en este artículo de investigación se presenta la parte de discusión e identificación, es decir, se acota el método al análisis de contenidos, por tanto, esta es una primera etapa de la investigación que se enmarca dentro de la línea del lenguaje, el discurso y la sociedad. El esquema se presenta como ciclo, al señalar la importancia de revisar las interpretaciones a la luz de las teorías de los sistemas discursivos poder-saber en un continuo.

Figura 1.0 Armazón metodológico. Representaciones discursivas de la homosexualidad en el sistema DSM IV (Fairclough, 2002, p. 63).

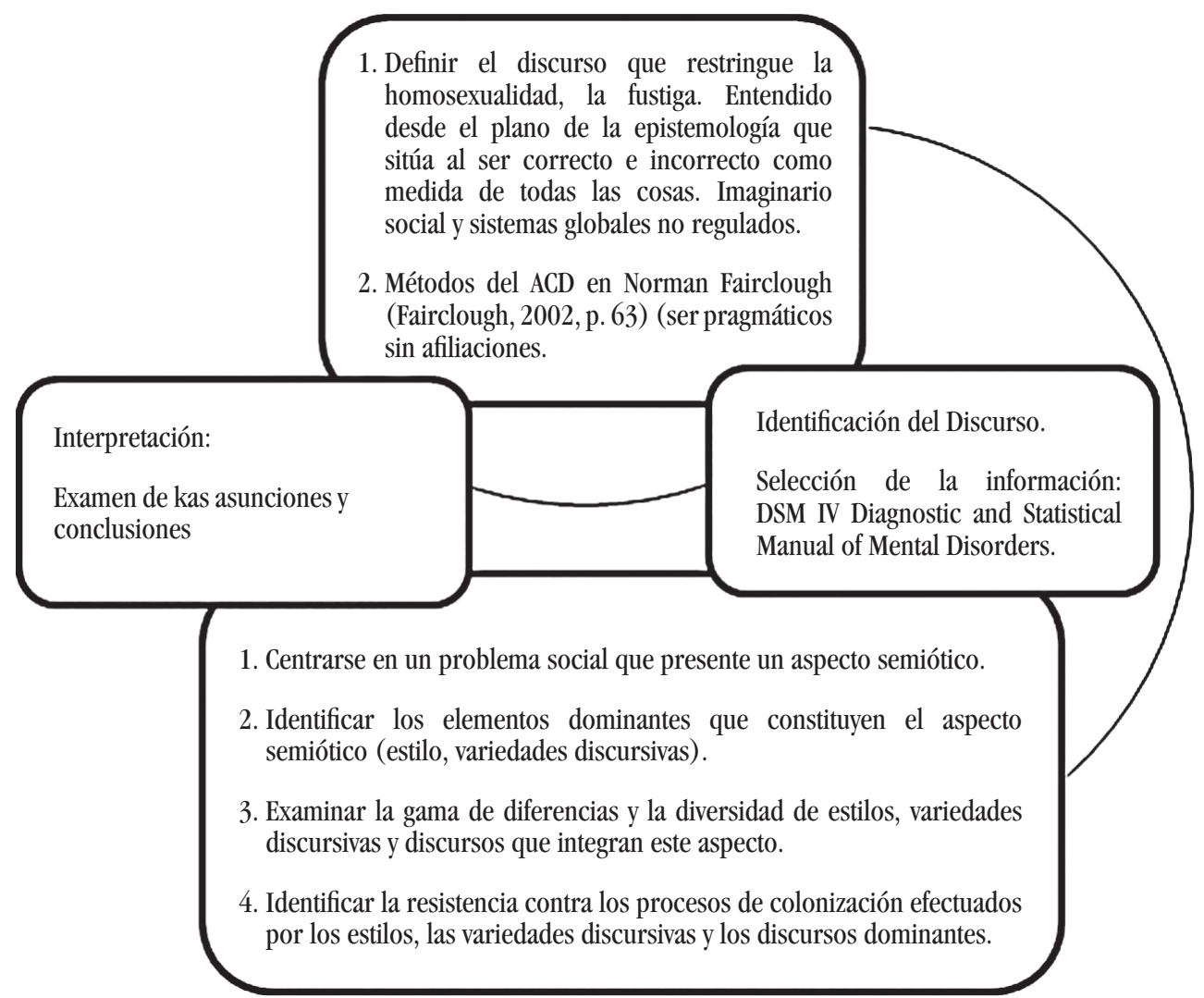

\section{Revisión conceptual}

En el desarrollo del texto se emplean expresiones propias del análisis del discurso que pueden parecer poco explícitas. Por esa razón, se incluye esta sección de revisión conceptual. 
Es preciso subrayar que los estudios o análisis del discurso buscan entender las adquisiciones, usos y estructuras de las representaciones mentales que se forman las personas respecto a las situaciones, como lo señala Van Dijk en su texto Discurso y Poder (2006). Además, las representaciones mentales están en un contexto determinado, esa relación supedita el análisis del discurso a sus interacciones con el poder de las instituciones en voz de diversos actores.

Pues bien, un actor que pronuncia un discurso (diagnóstico psiquiátrico para el caso de revisión) dentro o fuera de su contexto (médico) habla desde su condición de individuo y de sujeto, enuncia sus esferas políticas personales, estas interactúan con las esferas de otros individuos (periodistas, estadistas, tenderos, en fin) que procesan la información. Al mismo tiempo, esa persona habla en nombre de una institución científica, además, es miembro de una cultura, actúa como fuerza opositora de otras ciencias o de gobiernos que han legalizado el matrimonio gay, en suma, expresa "las actitudes o ideologías de su propio grupo. Y, finalmente, al hacerlo, él o ella está promulgando un sistema" (Van Dijk, 2006, p. 266).

A continuación se esquematiza el procesamiento del discurso en la conceptualización de Van Dijk, figura 2.0. La representación es un fenómeno de relaciones, es la relación entre la cognición del evento social y el discurso, asimismo, implica el procesamiento del discurso en el que interacciona el medio.

Figura 2.0 Relación entre la cognición del fenómeno social y el discurso.

(Van Dijk, 2007, p. 267)

Fundamentos cognitivos del discurso como las creencias políticas, morales y sociales del individuo: sus juicios y la representación en la memoria.
El interés sobre el fenómeno, que son las representaciones mentales que comparten los individuos en calidad de actores sociales involucrados en el fenómeno.

Relación entre la cognición del fenómeno social y el discurso.

El tratamiento de la información por terceros. Los medios de comunicación. Esta es una forma de procesamiento del discurso.
La participación de los actores, esta se cumple a través del discurso. En el caso estudiado en el diagnóstico. 


\section{Resultados ${ }^{4}$}

En 1952, bajo la tutela de la praxis, el DSM I se configura por las necesidades contables y estadísticas de la morbilidad de los trastornos mentales posteriores a la segunda guerra mundial5 . No obstante, la utilidad clínica que tiene esta primera versión del manual le imprime "la seriedad de la cartilla que es la afasia del poder", como alguna vez lo afirmó Estanislao Zuleta (1980, conferencia). Esa relación de lo visible (la cartilla) y lo que no se ve con tanta facilidad (el sistema de poder) puede establecerse mediante la siguiente cita respecto a la homosexualidad: "ha costado siglos poder afirmar abiertamente que no es una enfermedad, que no es una perturbación ni un delito, aunque costará algunos más confirmar que no es pecado para la mayoría de las confesiones religiosas" (Sánchez, 2011, p. 246).

En 1970, la convulsión social de Stone Wall dio lugar a la primera marcha del orgullo gay, en la que se reclamó la desvinculación de la homosexualidad del manual DSM. En este punto del texto y conforme a los cursos históricos, la desvinculación de la homosexualidad del manual es una resonancia política como se demostrará en párrafos posteriores. Ahora bien, las críticas que surgieron frente al DSM I no se referían a su configuración discursiva, sino a sus consecuencias plausibles: las terapias de reorientación o conversión sexual. Con esto, se dice que el trabajo empírico que adelantaron los psiquiatras en los años setentas fue de vocación política, porque no buscaban controvertir los movimientos sociales en beneficio de las minorías (los homosexuales).

En 1957, la psicóloga Evelyn Hooker publicó su estudio La adaptación del hombre abiertamente homosexual, en el que se demostraba, por primera vez, que los hombres homosexuales no se distinguían de los heterosexuales por su salud mental. En 1965, el libro 'Inversión sexual: las múltiples raíces de la homosexualidad' del psiquiatra Judd Marmor, argumentó que "la actitud hacia la homosexualidad es determinada por la cultura" (1965, p. 70). La Asociación Psiquiátrica de Estados Unidos, fundada en estos estudios, decidió en 1973 desvincular la homosexualidad como rótulo del DSM para sus próximas revisiones. Sin embargo, no reconoció la actitud política que cobraba el momento sociocultural de los sesentas y setentas al tomar esta decisión.

Una de las figuras preponderantes dentro de esa decisión fue la del psiquiatra Robert Spitzer (Ritter, 2001, p. 2). Él señala que la clasificación de los trastornos mentales en categorías discretas con los criterios de diagnóstico especificados ha traído problemas.

4 En esta parte del texto se presenta la contextualización del manual, en cada etapa de desarrollo de la sistematización metodológica propuesta por Norman Fairclough, se nombra el ítem que se adelanta al seguir el ciclo del análisis de contenidos y del análisis crítico del discurso.

5 Ver anexo 1. 
En el año 2001, Spitzer publicó un artículo científico titulado ‘Pueden algunos gays y lesbianas cambiar su Orientación Sexual? 200 participantes informaron un cambio de homosexual a heterosexual' (2001, p. 1). En este artículo, se estudiaron las terapias de reconversión sexual, evidenciando que la homosexualidad no tiene las características de una enfermedad mental, es decir, que no existe diagnóstico, ni tratamiento, aunque doscientos participantes indicaron un cambio en su orientación sexual.

\subsection{Descripción del método de construcción del manual DSM IV y otras ejemplificaciones del problema de estudio ${ }^{6}$}

Siguiendo la sistematización propuesta en el apartado anterior, es preciso mencionar la metodología empírica que se sigue dentro del manual para vislumbrar los aspectos discursivos más relevantes. El Comité elaborador del DSM-IV y los grupos de trabajo efectúan un proceso empírico en tres niveles, que incluyen: 1) Revisiones sistemáticas de la literatura hasta ahora publicada. 2) Re-análisis de los datos ya recogidos. 3) Estudios de campo. A continuación, se presentan diversos ejemplos discursivos en los que se apoya el desarrollo de la metodología propuesta en el presente texto y en el manual DSM.

El artículo de Spitzer $(2001$, p. 3) y su postura discursiva en cuanto a la homosexualidad y las terapias que se reportaron en su estudio corroboran la hipótesis represiva que supone al poder como un instrumento restrictivo, cuya mecánica es entorpecer o distorsionar la verdad. En este caso, el discurso individual pertenece a Robert Spitzer, pero, el discurso dominante es el del manual DSM. Es decir, aunque un individuo hable sobre el tema y devele su investigación, la forma institucionalizada cobra mayor peso respecto al diagnóstico y al consecuente tratamiento. Freud (1886, p. 1) afirmó en una carta a una de sus clientas que deseaba tratar a su hijo homosexual: "las terapias de reorientación sexual tienen consecuencias destructivas". Además, dichas terapias tienen prohibiciones jurídicas en países como Estados Unidos.

Con un estilo minucioso y actualizado, el método de revisión sistematizada del manual puede equipararse a las experiencias de Carl Vaernet y Martin Seligman (2002). Al primero de estos, por sus experimentos médicos con hormonas y dispositivos administrados en el campo de Buchenwald tratando así la homosexualidad. El segundo de ellos, por su discurso de la mecánica económica de productividad y eficiencia encubierta por la "ciencia psicológica positiva de la felicidad" (p. 67). Una mezcla contra actual que está sujeta a una condición política dentro del discurso clínico.

6 Parte uno de la sistematización o desarrollo de la metodología: problema social que presenta aspectos semióticos, es decir, la producción de sentido, los significantes y los discursos dentro del manual DSM. 
En efecto, la metodología que se sigue para la construcción discursiva del manual es un círculo de retroalimentación en el que los significantes del discurso están presentes dentro de la sistematización, es decir, no abandonan el discurso. Se debe renunciar a la siguiente hipótesis: La sociedad de psiquiatras no considera a la homosexualidad como un trastorno, porque al evaluar su metodología el esquema de círculo hace que la representación discursiva sobre el homosexual esté en revisión, o sea un trastorno ${ }^{7}$. Ahora bien, no la ve como enfermedad, sino como un subproducto de la <conciliación $>$ entre los valores y normas tradicionales; en la metodología para diagnosticar homosexualidad egodistónica se considera el grado de perturbación que reporta el paciente sobre su condición. Cuando se nombra la palabra <condición>, de inmediato en el discurso se imprime la hipótesis central del presente texto.

Los pacientes que no hayan elaborado dicha concordancia serán considerados homosexuales egodistónicos o de orientación sexual egodistónica. Al hacer una lectura de las teorías de Judd Marmor no se debe considerar a la identificación y orientación sexual en un sistema de coherencia rígida. Se debe vislumbrar el barniz de cultura sobre el sexo, la sexualidad y la identidad; cosas que se relacionan, pero que no son lo mismo, sólo que la excesiva reducción o ampliación del discurso lleva consigo ciertas dislocaciones.

Todas las cargas simbólicas, discursivas y contextuales que se elaboran sobre la sexualidad, siguiendo la tesis de Foucault, se fabricaron desde un sistema represivo de doble espiral: poder y placer. Hablar de la represión hacia la homosexualidad es un aire de transgresión que se mueve entre < práctica $>$ y < conciliación $>$ con regímenes que suscitan la contradicción, como lo anota (Foucault (1977):

Hablar contra los poderes, decir la verdad y prometer el goce; ligar entre sí la iluminación, la liberación y multiplicadas voluptuosidades; erigir un discurso donde se unen el ardor del saber, la voluntad de cambiar la ley y el esperado jardín de las delicias; he ahí indudablemente lo que sostiene en nosotros ese encarnizamiento en hablar del sexo en términos de represión; he ahí lo que quizá también explica el valor mercantil atribuido no sólo a todo lo que del sexo se dice, sino al simple hecho de prestar el oído a aquellos que quieren eliminar sus efectos. (p. 8).

7 En la actualidad, la representación discursiva que reposa sobre la homosexualidad es el estatus de revisión, diagnosticando a la homosexualidad egodistónica, que finalmente es homosexualidad. La representación es la conmutación del significado que hace referencia al contenido interno del discurso y el significante que concierne al contenido externo. Significados y significantes son categorías abstractas dentro del discurso que deben evaluarse para entender la representación, es decir, la construcción global de un discurso, en palabras distintas, las relaciones que existen entre creencias compartidas. 


\subsection{Críticas al sistema DSM IV y los elementos dominantes dentro del discurso institucional}

El sistema global de referencia DSM IV no solo fustiga a la homosexualidad de manera encubierta, también con las sexuālis diversus: BDSM, poliamor, asexualidad, en fin (Del Lagrace, 2005). En este documento se entiende por sexuālis diversus aquellas que escapan a las "estructuras diádicas dominantes" (Butler, 2002, p. 78). Estas nuevas formas de ver la sexualidad son dinámicas y no se atan a la "coherencia" de la identificación sexual y la orientación sexual.

El apartado sobre los Trastornos sexuales y de la identidad sexual inicia con un preliminar que revela un discurso soslayado en el que "se describen las disfunciones sexuales, las parafilias y los trastornos de la identidad sexual" (Manual DSM IV, 1995, p. 520). Entiende por trastornos de identidad sexual a los transgéneristas, travestis, transexual y sexuālis diversus dentro de los trastornos sexuales no especificados. La homosexualidad, en principio, se consideró un desorden de la orientación sexual y su contrapartida es la identidad sexual como un desequilibrio por extensión a la forma dominante del desorden psíquico.

Probablemente, la forma dominante (la homosexualidad) mantiene distancia social entre los médicos, los pacientes y la autoridad del médico, a diferencia de los travestis, por ejemplo, en cuanto a la forma en que se desarrolla la interacción; sin embargo, existen otras formas que son más <<democráticas $>>$, formas en las que los médicos "restan importancia a su autoridad" (Wodak, 2002, p. 183). Le restan importancia al manual, pero sopesan el ejercicio de su profesión en él. La idea del sexo «reprimido» y las sexualidades «marginales» no son una simple cuestión de teoría y manuales. El rigor del método multiaxial de valoración clínica se relaciona directamente con el énfasis discursivo sobre una represión de doble arista (placer y poder), que se destina a modificar las «conciliaciones» sobre el discurso clínico que representa el homosexual como objeto de estudio.

Bajo la premisa de las libertades sexuales "concedidas" bajo la tutela relativa de la psiquiatría y la política, se pretende señalar a las formas sutiles, pero muy astutas del poder. Un orden del discurso no es un sistema cerrado o rígido, sino mas bien un sistema abierto que queda expuesto al peligro como consecuencia de lo que sucede en las interacciones efectivas (Wodak, 2002, p. 183). La praxis y la disquisición del sistema de referencia conducen a una interacción semiótica entre una estructura discusiva y un enfoque clínico de control y polifonía del poder. 
El modelo sobre los mecanismos tensionales y los refuerzos negativos de ideas pulsionales son los que se tipifican en el DSM. La prohibición de determinadas prácticas como el fetichismo, el voyerismo, la zoofilia, el exhibicionismo, la pansexualidad, el contemporáneo BDSM (sexualidad extrema no convencional) y obvia la recriminación de la "homosexualidad egodistónica" y toda la censura impuesta por el sistema referencial son dispositivos secundarios respecto al aparato de dominación: el diagnóstico y su respectivo tratamiento.

El estudio de las perversiones sexuales es una intensificación de los poderes porque se cree que aquellos que realizan actos abiertamente perversos carecen de la estabilidad emocional pertinente, lo que los hace diferentes, anormales, es decir, distintos de los normativizados que han elaborado sistemas de coherencia rígida y una conciliación moralmente compatible con las prácticas sociales. Además, la multiplicación de los discursos que analizan con minucia los excesos y las insatisfacciones sexuales siguen siendo ese organismo terapéutico que usa distinciones temporales arbitrarias, establece cánones de funcionalidad y productividad poco o nada ajustados a los contextos sociales 0 , contrario a ello, encuentra explicaciones totalitarias en los contextos sociales.

El eretismo discursivo generalizado que describe Foucault se hace patente en el manual DSM y en la negación médico psiquiatra sobre la hegemonía discursiva de la herramienta que estandarizó las patologías de la mente con argumentos cientificistas de tipo: «desórdenes bioquímicos cerebrales» que aún no se pueden verificar, han construido todo un aparato dominante. Un aforismo sencillo diría que la negación es aceptación por extensión.

La historia del manual DSM, en la última década del siglo XX y la primera década del siglo XXI se asocia a la expansión comercial de los tratamientos vía fármacos. Es posible que se haya codificado todo el recetario que presenta el manual y reafirmado de una manera acelerada la hipótesis represiva; la "aceptación" se determina como una prohibición encubierta para tornarla moralmente admisible y técnicamente lucrativa. Michel Foucault toma distancia de los hitos históricos como el neoliberalismo y la globalización para explicar los mecanismos y aparatos represivos. Las explicaciones a nivel macro distraen la atención al atribuirle todo el peso argumentativo a conceptos tan generales como los que se mencionaron antes.

Lo esencial del discurso no está en sus aspectos genéricos, sino en la hipocresía que en ellos se sospeche. El tratamiento otorgado por el manual DSM a las histerias femeninas se equipara al lugar que le da a la homosexualidad egodistónica, no es cosa distinta a esa hipocresía y a esa actuación tolerable frente a la sexualidad y sus diversas 
manifestaciones, no pueden ser disímiles a la transgresión de las normas. Ahora bien, no vale hacer una división entre la descripción del manual y las acciones investigativas de carácter psiquiátrico, porque esas fuentes de información se retroalimentan en un mutismo indisoluble. En efecto, lo que podría llamarse un discurso institucional se funde todo el tiempo con las prácticas de comprobación (investigación sobre nuevas enfermedades mentales), evaluación, ridiculización (diagnóstico y tratamiento).

Las ortodicciones del discurso psiquiátrico se evidencian en los mecanismos de confesión que se labran en la consulta médica. Además, los controles sociales que se ejercen con el lema de una vida sexual plena, en la que todas las publicaciones ciñen un canon que se aleja del homosexualismo y de las perturbaciones sobre las prácticas normativas. Dichas ortopedias incitan el espiral poder - placer, también lo conservan en su seno institucional. En el caso del discurso psiquiátrico, la codificación implícita de los 'males' del sexo y las distorsiones de la sexualidad son las llamadas ortodicciones al respeto de las normas contra el adulterio.

\subsection{Técnicas polimorfas del poder en el manual DSM IV como las formas dominantes de discurso frente a las alternativas sexuālis diversus sin discurso ${ }^{8}$.}

Las prohibiciones, censuras, los rechazos; en suma, las denegaciones que la hipótesis represiva reagrupa en un mecanismo central que dice no, sin duda, son piezas de un papel global y táctico que desempeña el DSM en una técnica de poder; subyacente a la edición de enfermedades mentales. Permea todo un discurso sociopolítico; reafirma la hipótesis represiva que ha construido un imaginario de las sexualidades ubicándolas en las periferias del discurso.

Las técnicas de control médico se denominan 'ilegalidades psiquiátricas' en la homosexualidad y en las sexuālis diversus cuando son <conflictos $>$ entre la identidad sexual y la orientación sexual. El manual reduce, en el campo del lenguaje, a la demonización homosexualidad egodistónica; controla su libre circulación en el discurso como una apropiación médica del término psicológico egosintónico: autoimagen y autoestima del individuo; apaga las palabras que hacen presente, con demasiado vigor, las alusiones a la homosexualidad y a las sexuālis diversus; las enreda con especificaciones de receta.

Los efectos iatrogénicos de un discurso psiquiátrico sistemático continúan alimentándose, puesto que la comorbilidad en la valoración multiaxial es posible, es decir,

8 Parte tres y cuatro de la metodología descrita anteriormente. Se presentan las maneras discursivas del manual frente a las neosexualidades que carecen de un discurso, es decir, la forma dominante e institucional frente a las prácticas no convencionales. 
el discurso < práctico > del manual engendra imaginarios de enfermedades mentales coexistentes con la homosexualidad egodistónica (el travestismo). Cabe resaltar, dentro de las especificaciones técnicas y metodológicas del DSM IV, las salvedades 'culturales' que prometen librarse de los sesgos del discurso; sin embargo, la histerización de los cuerpos dentro del manual es tal que la valoración de un síntoma frecuente la dictan seis meses de inconformidad con los valores y normas tradicionales. Se lee en el discurso del DSM IV como una incoherencia con la imagen del individuo y no con el sistema moral predominante.

Las formas del poder en el DSM se podrían clasificar en cuatro, distintas a la censura soslayada. La primera de ellas es la propagación del poder y del objeto sobre el que se ejerce, es decir, enseñar a los psiquiatras el uso del manual y apoyarlo sobre los enfermos (estudios de campo); la segunda es el hostigamiento de las sexuālis diversus (investigaciones sobre la sexualidad extrema no convencional), además, la caracterización de las perversiones; la tercera es el mecanismo de la concesión $0<$ aceptación $>$ de la homosexualidad (revisión del tema por parte del comité elaborador del manual), pero no del travestismo; y por último, están las instituciones de control como los grupos de investigación que alimentan al manual y sus supuestos vacíos que nutren a los grupos 0 científicos de las ciencias de las enfermedades mentales (El círculo de retroalimentación que se nombró anteriormente).

Michel Foucault se pregunta: "¿Cómo se logró constituir esa inmensa y tradicional extorsión de confesión sexual en formas científicas?" (1999, p. 98). El examen multiaxial del que tanto se ha hablado en el documento se entiende como esos nuevos métodos del hacer hablar; da lugar a la existencia de los demás mecanismos de control. Un accidente, una desviación, un trauma, un exceso pueden conducir a una enfermedad mental. No obstante, la latencia de la sexualidad es un argumento en beneficio de la caracterización de aspectos de la enfermedad mental, es decir, la forclusión de un significante fundamental en relación con el sexo.

En este punto se hace evidente el sistema de mecanismos por refuerzos tensionales que se diagnostican y medican, en una relación negativa entre poder y sexo, límite y carencia. La regla que subyace al sistema estandarizado para los males de la mente y la sexualidad es el poder. Para Foucault el poder es esencialmente lo que dicta al sexo su ley.

Por otra parte, Peter Sloterdijk (1983), en su texto Crítica de la razón cínica, muestra cómo las "prescripciones de prudencia", que señala Foucault (1998, p. 79) en La Historia de la Sexualidad I, no se hacen patentes en este caso de estudio. Los bloques tácticos del discurso y de los focos poder-saber, placer-poder revelan un doble 
condicionamiento, pero de una manera cínica, tan vulgar como un recetario para preparar antipsicóticos, ansiolíticos y antidepresivos en un mercado de cajas negras y agujeros argumentativos.

\section{Conclusiones}

El análisis de contenidos ${ }^{9}$ que se describió en la metodología, su consecuente desarrollo en el apartado de resultados y las críticas que se elaboraron en torno al DSM IV permiten vislumbrar el debilitamiento de las restricciones morales sobre la homosexualidad, como se aseguró en la introducción. No obstante, las "significaciones" (Butler, 2002, p. 140) del travestismo y de las sexuālis diversus dan cuenta del nivel de falsa indulgencia que se le otorga a la orientación y a la identificación sexual. En este paraje puede afirmarse que la represión sobre el sexo y sus formas son fruto de la "histerización" (Butler, 2002, p. 100) de los cuerpos como referencias válidas para editar perversiones y plasmarlas en un manual.

Tal es el caso de Richard von Krafft-Ebing (1905), un psiquiatra que dedicó todo su trabajo a especificar, calificar, apreciar y jerarquizar las perversiones sexuales. En su texto Psicopatía del sexo (1886) en donde se identifica la paradoxia, o el deseo sexual experimentado en etapas de la vida equivocadas, la anesthesia como escasez de deseo, la hyperesthesia que es deseo excesivo y la paraesthesia que es el deseo sexual sobre un objeto equivocado en el que se incluía la homosexualidad. Este es quizá, uno de los referentes más parecidos a lo que se conoce en la actualidad como el Manual Diagnóstico y Estadístico de los Trastornos Mentales. Es preciso afirmar que fruto de las nuevas investigaciones se sigue medicando bajo los preceptos de 1886 quitando la palabra homosexualidad del manual por ser un tema de carácter político acentuado. En conclusión, el esquema circular descrito sigue operando, manteniendo la representación y la significación discursiva.

La reconsideración que se plantea es ¿qué sucedería con la institución del manual si se quitara el travestismo y las sexuālis diversus como trastornos de la mente? La homosexualidad se editó llegando a la forma egodistónica recordando la hipótesis represiva Foucaultiana. Al realizar un análisis de contenido en documento clínico de referencia se observa cómo el <equilibrio> discursivo se alteró, quizá, si el travestismo se elimina del manual, será muy evidente la desconstrucción discursiva y el esquema del circulo sería seccionado. Finalmente, la bisección sería completa porque se quitarían los

9 El análisis de discurso acotado que se efectuó resaltó el discurso dominante (manual DSM IV) frente a las formas no discursivas sino prácticas (neo sexualidades). Sus categorías resaltan los aspectos estilísticos del discurso que para el caso de estudio son neutros, las tendencias que son de discurso de diagnóstico directo a diagnostico soslayado como se nombró en el texto. 
vestigios políticos y morales. Cualquier forma de deseo que no tenga como fin último la fecundidad o las insinuaciones simbólicas de la misma, es una perversión. Por ello, la violación es un acto aberrante, pero no una perversión, porque de ella podría derivarse el embarazo. Otro ejemplo sobresaliente, son las expresiones estéticas travestidas que rayan con lo socialmente inaceptable: algo extraño que debe medicarse, por resultar aberrante y perverso.

Otro argumento que apoya la reconsideración de los imaginarios sobre el homosexual en el manual DSM IV es la tesis que Philippe Ariés (1987, p. 65) retoma de Michael Pollak sobre los modelos de sociedad que en conjunto se acuerdan sobre las representaciones que de sí mismos hacen los homosexuales y que esta concordancia se debe a la deformación de las imágenes y los papeles. Dicha distorsión podría explicarse desde el fracaso de los modelos, una matriz heterosexual, esencialmente occidental (modelos patriarcales, matriarcales), debidos al cambio en la antropología de la virilidad y la feminidad, también se registran las mutaciones del trabajador y del tipo que explica Ernest Jünger en su texto El trabajador, Dominio y Figura, que, sin duda alguna, ha modificado el imaginario hacia la "aceptación", y es allí donde los temas de la ciencia psiquiátrica se ven languidecer. "La tolerancia frente a la homosexualidad derivaría de un cambio en la representación de los sexos, no solo de sus funciones, de sus roles en la profesión y en la familia, sino de sus imágenes simbólicas" (Ariés, 1987, p. 3).

La hiper-saturación discursiva sobre la sexualidad tolerada deriva de las variaciones en las representaciones sociales del homosexual, no obstante, el discurso clínico es fiel a su rigor. Un discurso construido de esa manera no puede ser más que la expresión de los dispositivos poder-placer-saber que se han implantado desde la ciencia psiquiátrica. Y el solo hecho de que se haya pretendido hablar desde el punto de vista aparentemente purificado y neutro: cientificista, incapacidad o rechazo a hablar del sexo mismo, en esa dinámica poder -saber "se refirió sobre todo a sus aberraciones, perversiones, rarezas excepcionales, anulaciones patológicas, exasperaciones mórbidas" (Foucault, 1998, p. 67).

\section{Referencias bibliográficas}

Alcott, A. (1836). The young man's guide. Boston: Perkins and Marvin.

Ariés, P. (1987). Sexualidades occidentales. Barcelona: Paidós. 
Babiszenko, D., \& Lutereau, L. (2011). La homosexualidad femenina en el psicoanálisis de J. McDougall. Psicoanálisis, 33(1), 21-38. Argentina: Universidad de Buenos Aires.

Bataile, G. (1978). Historia del ojo. España: Tusquets.

Barthes, R. (1974). La semiología. Buenos Aires: Tiempo Contemporáneo.

Barthes, R. (1973). Por ambas partes, Ensayos críticos. Barcelona: Seix Barral.

Beck, U. (1994). Modernización Reflexiva. Madrid: Alianza Editorial

Butler, J. (2002). Cuerpos que importan: sobre los limites materiales y discursivos del "sexo". Buenos Aires: Paidós.

Butler, J. (2009). Dar cuenta de sí mismo. Violencia ética y responsabilidad. Buenos Aires: Amorrortu.

Colorado, C. (2010). Una mirada al Análisis Crítico del Discurso. Entrevista con Ruth Wodak. Discurso \& Sociedad, 4(3), 579-596. Universidad Pompeu Fabra.

Del Lagrace, V. (2005). Corpus queer: bodies in resistance, Transpalette, Emmetrop. Bourges: France September 2005. (exhibitions)

Del Lagrace, V. (2005). Intersex 101: The Two Gender System as a Human Rights Abuse. Berlin: NGBK gallery (exhibitions).

Asociación Americana de Psiquiatría. (1994). DSM IV, Manual diagnóstico y estadístico de los trastornos mentales. Estados Unidos.

Fairclough, N. (2001). Language and Power. Londres: Longman.

Fairclough, N. (2003). Analysing Discourse: Textual Analysis for Social Research. Londres: Routledge.

Foucault, M. (1988). Las palabras y las cosas. México: Siglo XXI.

Foucault, M. (1998). Historia de la sexualidad I: La voluntad de saber. México: Siglo XXI.

Halberstam, J. (2005). In a Queer Time and Place: Transgender Bodies, Subcultural Lives. New York: New York University Press.

Halberstam, J. (2003). The Transgender Look. In The Bent Lens: A World Guide to Gay and Lesbian Film, pp. 18-21. Los Angeles, CA: Alyson Books.

Hooker, E. (1957). The adjustment of the male overt homosexual.Journal of Projective Techniques, 21(1), 18-31. Los Angeles: Universidad de California. 
Innis, H. (1952). Changing Concepts of Time. Toronto: University of Toronto Press.

Jiménez, R. (2012). La génesis de las parafilias sexuales y la homosexualidad egodistónica: el Modelo de los Mecanismos Tensionales. Avances en Psicología Latinoamericana. España: Universidad de Málaga.

Jünger, E. (1990). El Trabajador. Madrid: Tusquest.

Krafft-Ebing, R. (1999). Psychopathia Sexu lis. Alemania: Bloat Books.

Kaiser, C. (1997). The Gay Metropolis. Broadway: Group West.

Gamboa, I. (2006). La Constitución de Trastornos Sexuales en la Psiquiatría. Diálogos, 7(1), 242290. Costa Rica: Universidad de Costa Rica.

Gee, J. (2005). La ideología en los discursos. Madrid: Morata.

González, C. (2001). "La identidad gay: una identidad en tensión”, Saberes y Razones primavera-verano (paper).

Martín, M. (2011). Aproximación histórica al tratamiento jurídico y social dado a la homosexualidad en Europa. Estudios Constitucionales, 9(1), 245 - 276. Santiago: Centro de Estudios Constitucionales de Chile, Universidad de Talca. Recuperado de http://www.scielo.cl/scielo. php?pid=S0718-520020110001 00009\&script=sci_arttext

Marmor, J. (1972). Homosexuality in males. International Journal of Psychiatry, vol. 10, no. 1. (paper).

Marmor, J. (1972). Homosexuality mental illness or moral dilemma? International Journal of Psychiatry, vol. 10, no. 1. (paper)

Preciado, B. (2009). Historia de una palabra. Ensayo. Madrid: Anagrama.

Preciado, B. (2009). Género y basura. Ensayo. Madrid: Anagrama.

Ritter, M. (2001). "Study: Some Gays Can Go Straight". The Washington Post. Revisado en internet el 11 de octubre de 2013. http://www.washingtonpost.com/wp-srv/aponline/20010509/ aponline013921_000.htm

Rodríguez, A. (2013). Las escaleras de escher: la transversalización de género vista desde las capacidades del estado. Estudios de Género CEPAL. (paper)

Rojas, M. (2006). El imaginario. Civilización y cultura del siglo XXI. Buenos Aires: Prometeo.

Sáez, J. (2013). Guía para la gestión policial de la diversidad. Madrid: Editorial Plataforma por la Gestión policial de la Diversidad. 
Sáez, J. (2013). Discriminación y Comunidad Gitana. Madrid: Editorial Plataforma por la Gestión policial de la Diversidad.

Seligman, M. (2002). Authentic Happiness: Using the New Positive Psychology to Realize Your Potential for Lasting Fulfillment. New York: Free Press.

Sloterdijk, P. (1983). Crítica de la razón cínica. Madrid: Siruela.

Spitzer, R. (2001). Can Some Gay Men and Lesbians Change Their Sexual Orientation? 200 Participants Reporting a Change from Homosexual to Heterosexual Orientation. Biometrics Research Department, NewYork State Psychiatric Institute, New York. Department of Psychiatry, Columbia University. (paper).

Téllez, F. (2012). Narración audiovisual transnacional en la homosexualidad. Comunicación: revista Internacional de Comunicación Audiovisual, Publicidad y Estudios Culturales. España: Universidad de Sevilla.

Téllez, F. (2013). Culturas homoeróticas televisadas. Ponencia. III Congreso “ciencias, tecnologías y culturas. Dialogo entre las disciplinas del conocimiento. Mirando al futuro de América Latina y el Caribe. Hacia una internacional del conocimiento". Chile: Universidad Santiago de Chile.

Van Dijk, T. (2000). Estudios del discurso. Buenos Aires: Gedisa.

Van Dijk, T. (2011). Sociedad y Discurso: Cómo influyen los contextos sociales sobre el texto y la conversación. Barcelona: Gedisa.

Van Dijk, T. (2007). Discurso y Contexto. Una aproximación cognitiva. Barcelona: Gedisa.

Vidarte, P. (2007). Ética Marica. Proclamas libertarias para una militancia LGTBQ. Madrid: Egales.

Vidarte, F. (1999). Homografías. Madrid: Espasa-Calpe.

Wittig, M. (1973). El cuerpo lesbiano. España: Pre-Textos.

Wodak, R. (2002). Methods of Critical Discourse Analysis (Introducing Qualitative Methods series). EEUU: Sage Publications.

Zuleta, E. (2000). Elogio a la dificultad y otros ensayos. Cali: Fundación Estanislao Zuleta. 


\begin{tabular}{|c|c|c|c|c|c|}
\hline \multirow{7}{*}{ 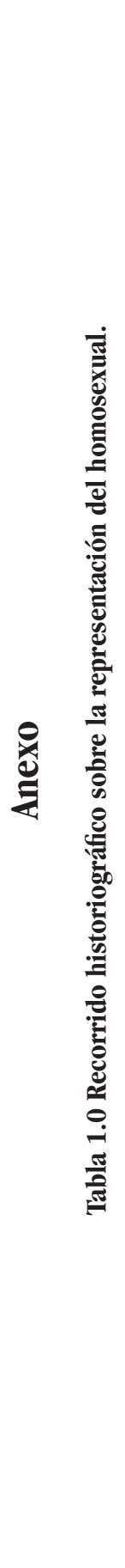 } & 일 & 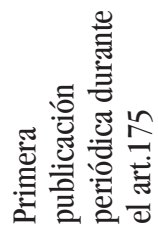 & 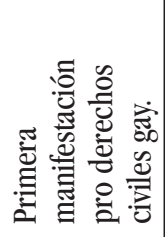 & 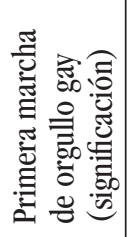 & 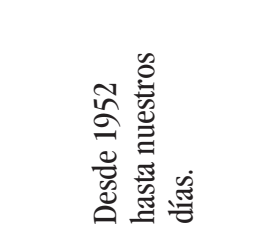 \\
\hline & 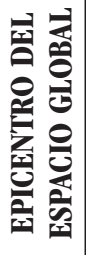 & 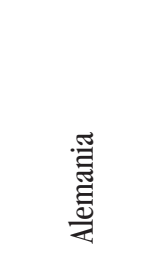 & 笁 & 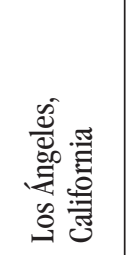 & 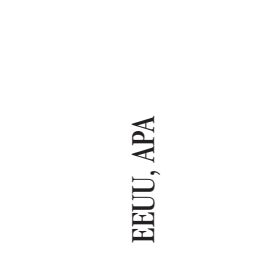 \\
\hline & 苞 & 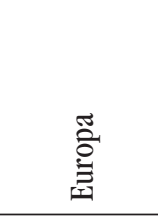 & 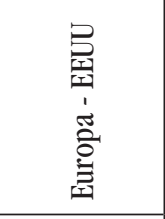 & 疍 & 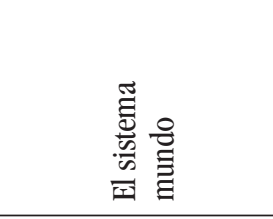 \\
\hline & 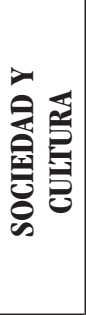 & 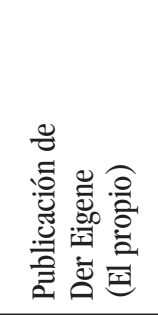 & 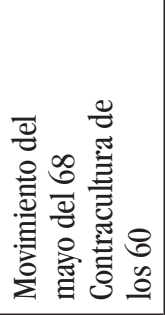 & 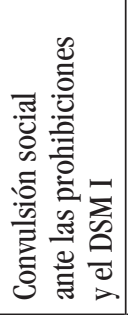 & 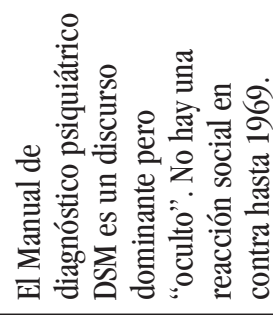 \\
\hline & 蒠 & 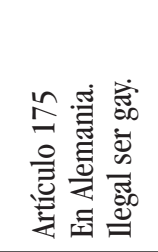 & 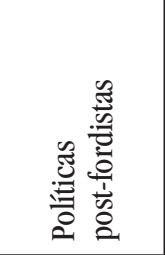 & 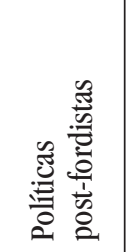 & 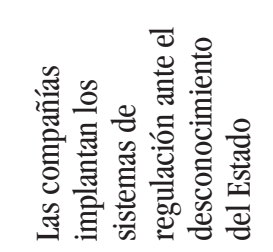 \\
\hline & 预 & 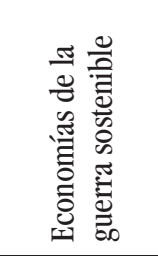 & 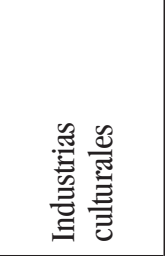 & 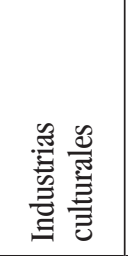 & 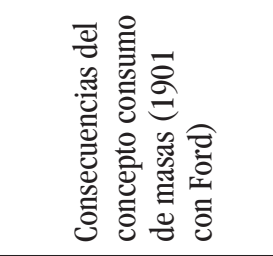 \\
\hline & 命 & $\frac{\tilde{a}}{\hat{\sigma}}$ & 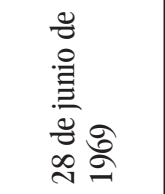 & 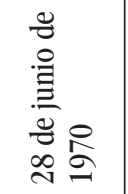 & $\stackrel{\tilde{2}}{\approx}$ \\
\hline
\end{tabular}

